\title{
Using Performative Art to Communicate Research: Dancing Experiences of Psychosis
}

\author{
Katherine Boydell \\ From "Using Performative Art to Communicate Research: Dancing Experiences of Psychosis," by Katherine \\ Boydell, 2011. In Canadian Theatre Review, DOI 10.3138/CTR.146.12, pp. 12-17. Copyright (C Canadian \\ Theatre Review, 2011. Reprinted with permission from the University of Toronto Press.
}

This paper highlights a collaborative effort to bring art and science together. In the field of arts-based research, collaboration between social scientists and artists is critical. ${ }^{1}$ Horsfall and Titchen state that "critical creativity as methodology disrupts traditional edges and enables participation of people in the research who are unlikely to engage in philosophical, theoretical and methodological study, but who can understand its assumptions through embodied experience ... [It] opens up endless spaces for genuine democratization of knowledge creation" (156). It was this type of democratized space that we wanted to create. We believed that bringing artists and scientists together would contribute to minimizing boundaries that often exist between these two worlds. We found that our collaboration provided a chance for meaningful dialogue and partnership. Additionally, as Jones states, "reaching across disciplines and finding co-producers for our presentations can go a long way in insuring that, rather than amateur productions, our presentations have polish and the ability to reach our intended audiences in an engaging way" (71).

Participant observation field notes and audiotaped transcripts of individual meetings between choreographer and social scientist and between creative and research teams over a six-month period were used to analyze our interchange and document the ways in which the research and artistic teams worked together across very different disciplines to communicate research findings through dance. The unfolding process was characterized by ongoing negotiation to balance differing viewpoints and opinions regarding how to take textual data from young people experiencing psychosis and translate it into a performative form. This required a shift in thinking by the research team in order to provide the creative team with the space to (re)interpret the data in the form of movement and music. The choreographer and dancers faced an artistic challenge-to "perform" first episode psychosis in a way that captivated an audience and reflected empirical research findings. ${ }^{2}$

As an academic in the health sciences field, I have experienced repeated frustration with respect to typical forms of academic currency-namely, peer reviewed publications and scientific presentationsand the fact that they tend to reach only a very limited audience, primarily other academics. While this is important, there are many other stakeholders, including service providers, policy makers, families, patients, and the general public who need to be aware of the findings of our research. I am particularly interested in how the creative arts can be used in the design, process, analysis, interpretation, and communication of research results. Can critical research findings be elicited and portrayed through the arts? Can such portrayals promote useable knowledge and understanding? Gadamer stated that all 
attempts at experiential knowing are aesthetically oriented (71), and it is only recently that the qualitative research literature has included artistic interpretation of data. An increase in arts-based approaches to research has been recently noted, largely in the educational realm and more recently, in health and social care. Both Norman Denzin and Kip Jones advocate for a performative model of social science and a reconceptualization of the relationship between performance and representation of academic research.

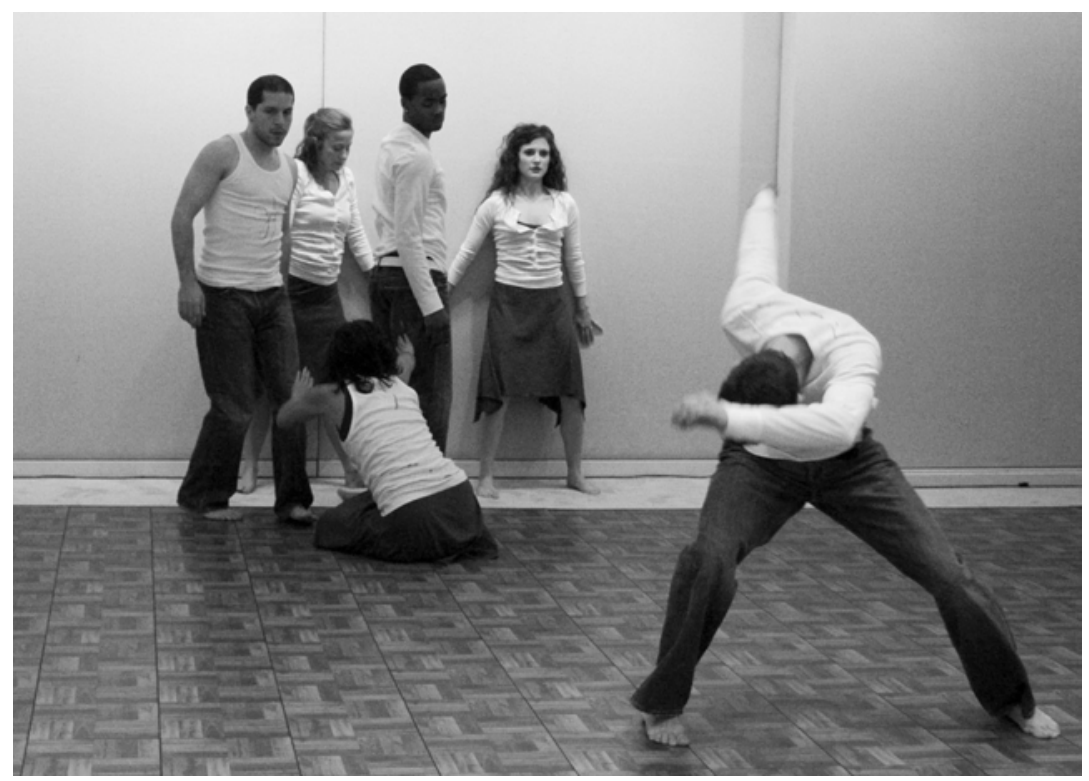

Hearing voices (l-r): Mariano Abarca, Lisa Collins, Nicola Pantin, Shavar Blackwood, Courtnae Bowman, and Jeff Dimitrou. Photo by Ashley Hutcheson

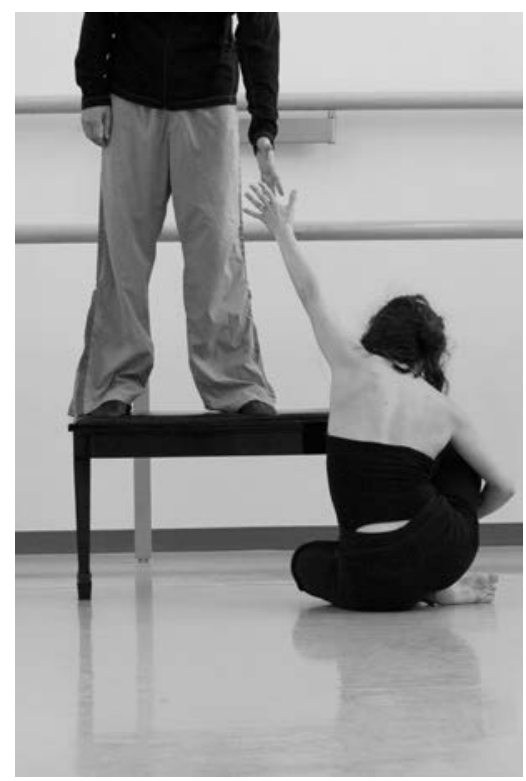

Photo by Ashley Hutcheson

The availability of "knowledge translation" funds from a research grant presented an opportunity to use the genre of dance to communicate qualitative research findings to multiple audiences. I believed that the choreographic and research processes were similar in terms of the essential role of interpretation. The intention was to use dance as a communicative tool for representing data on early psychosis and create an opportunity for people to become aware of psychosis in an accessible, creative, and thoughtful way, but also to provoke and perhaps disrupt the everyday assumptions individuals hold about mental health issues in general, and psychosis in particular. Young people told us that had they known that what they were experiencing may have been early signs of psychosis, they might have sought help earlier. They (and their families) identified stigma as a barrier to seeking help. Consequently, it was critical to the research team that research results be communicated beyond academia—targeting a broader audience, including young people, their families, service providers, educators, and the general public. 


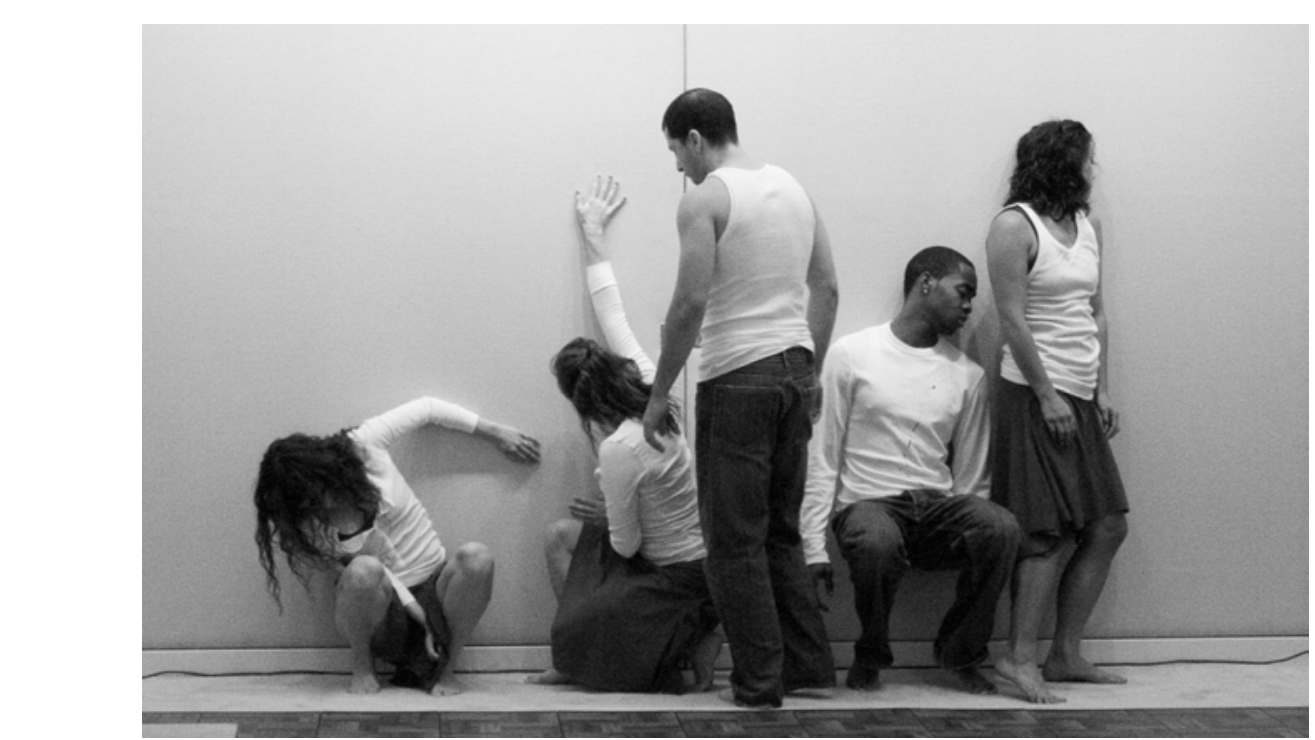

The anguish of psychosis (I- r): Courtnae Bowman, Lisa Collins, Mariano Abarca, Shavar Blackwood, and Nicola Pantin. Photo by Ashley Hutcheson

The dance was based on a multiple case study involving an in-depth examination of the pathways to mental health care. It included sixty interviews with young people and their significant others (including parents, general practitioners, friends, psychiatrists, teachers, and case managers) involved in the pathway to mental health care, as well as related documents and observational data. Our findings ${ }^{3}$ highlighted the complexity and connectedness of the family, school, community, and treatment system in the lives of young people. Results also depicted the illness experience in the pathway to mental health care. Although each person's pathway was unique, commonalities included: the difficulty in detecting psychosis by general practitioners, psychiatrists, educators, friends, and family members; symptoms of isolation and paranoia that prevented young people from disclosing their experiences and seeking help; the important role of the school; and the widespread shortage of knowledge about psychosis.

When we started to create the dance, we realized the challenge in taking the subject of psychosis and the genre of dance and combining them to communicate the experience of young people. Many discussions ensued regarding the ability of dance to explore knowledge physically, emotionally and mentally, allowing the audience to enter into the experience. Les Todres' work on embodied inquiry that attends to the relationship between language and the experiencing body is relevant here. Embodied research is based on the traditional phenomenological notion of the "lived body" and "lived experience" which suggests that knowledge has to do with lived experience. Embodiment is seen as an insightful and multidimensional means of linking body, movement, and force as embodied rhythms of how it is possible to be present, to live, to experience, to express and to understand individuals from many viewpoints and in particular contexts. Embodied inquiry focuses on the relationship between language and the experiencing body, and has the capability of highlighting the lived experience of individuals. Todres comments that it allows for "the possibility of going through the experience in a more enacted way", allowing participants to "come to understand the phenomenon in a more intuitive way" which "may provide further insights" (57). 
The academic-artistic partnership was characterized by managing reservations and taking risks. The risk I felt I was taking as an academic related to taking on a novel form of knowledge translation. I took comfort in Carl Bagley and Mary Beth Cancienne's work, as they are among the few educational researchers who have represented research through movement and dance. Because of the recency and novelty of this approach, Bagley and Cancienne were extremely cautious and chose to choreograph movements that were mostly literal and that closely represented the words of their research participants. I was, however, prepared to take some risks in terms of moving away from solely literal movements. In this case, choreographer Siona Jackson was given explicit creative license to include movements that were not so closely tied to the data itself, but that reflected the emotions of young participants.

In order to work together and discuss the research findings in depth, the dance choreographer (and her creative team) became immersed in the data, consisting of anonymized transcripts and observational and reflective field notes. As such, they accessed case study summaries as well as some of the actual anonymized transcripts.

The experience of creating the dance highlighted the ongoing adjustments made as the choreography was scripted and ensuing interactions emerged between the creative and research teams. The struggle between the content and the aesthetic qualities of the dance was paramount in this process - the issue of balancing didactic and aesthetic claims. I questioned what may have been sacrificed for the sake of performance and the choreographer questioned what may have been sacrificed for the sake of the research. For example, would leaving the performance open to a greater level of interpretation result in a product that was less true to the research? We arrived at a mutual agreement that it was essential to maintain the integrity of the key features of the experience; however, the ways in which to do so were frequently ambiguous.

Tensions have been documented between the academic literature, educational needs of researchers who are developing arts-related health research projects for the purposes of knowledge translation, and the aesthetic requirements of these projects that make the work interesting, complex, and engaging. ${ }^{4}$ This work requires a balance between personal engagement in the material, which often deals with complex and intimate lived experience, while remaining focused on the needs of the research project, including the systematic examination, analyses and interpretation needed for a rigorous approach to the work.

The creative team noted that a dancer needs to embody the material he or she performs or "translates" in addition to having an intellectual understanding. The research team realized that a dancer also uses his or her own personal experience in the portrayal of a character in order to relate fully to the dramatic material, thus contributing to the narrative research material. 


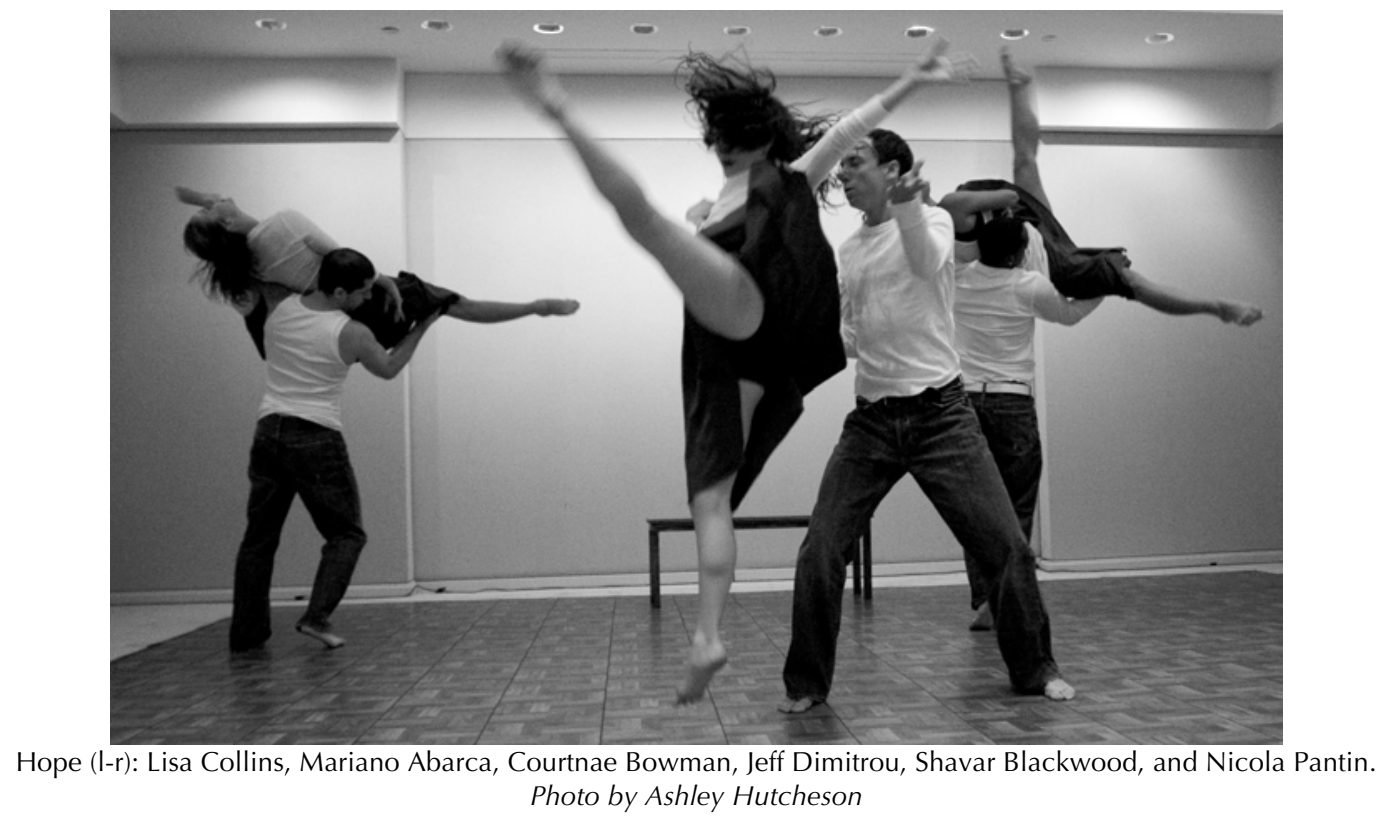

When the choreographer asked me to share some of the themes that emerged-actual words or a series of words - to help convey the research findings to her and to inspire the choreography, I felt confident and trusted that she would represent the results that were emerging in a meaningful and evocative manner. I provided her with words that represented a dialectic, but occurred along a continuum in the stories of the experiences of young people and their significant others as they navigated and negotiated pathways to care. I felt that it was important that the isolation, the uncertainty, the fear, the hopelessness-but also the hope, the joy, the connection, and the moving beyond the illnesswas highlighted.

Following an overview of psychosis and the field of early intervention, the research team highlighted the richness of the ten in-depth qualitative case studies. We talked about the complexity of the pathway, and the fact that although every young person's pathway was unique, there were common experiences across all cases. There was a great deal of help-seeking activity vis-à-vis subtle and not so subtle changes taking place (Boydell et al., "Youth Experiencing"). There were a number of persons and multiple systems involved in help-seeking activities; however, they rarely communicated with each other. There were many failed attempts at accessing appropriate services and supports and these efforts were conceptualized as "missed opportunities." We wanted these themes conveyed in the dance.

The analysis involved a narrative or dramatic coding of the transcripts ${ }^{5}$ whereby text was identified to be used for particular narratives, or for informing character or scene development in the dance. This process helped to identify the segments of text that were used in the musical score accompanying the dance. The choreographer used a script as an organizational tool to track activity presented in the performance and provide a reference of what she was trying to convey. The script was required due to the multiple meetings, articles, and data summaries that were somewhat overwhelming. It helped to condense information into a story-like dance that would educate, rather than overwhelm, an audience. The challenge was to privilege the voices of the particular, lived experiences of psychosis, yet also to 
emphasize the universality of the experience. The script marked out the location of the dancers and props (the bench), type of mood being expressed, musical and dancer cues, and emotion (such as heavy breathing). Once the basic script was established, there was freedom to layer the stories and the choreography. The script also served as a communication tool for the composer; the score was incorporated from the beginning, so that the ideas on the page inspired the music.

We agreed that it was possible to focus on the particular-the narratives of two young people with psychosis, as well as the universal-common themes across the descriptions of all pathways to care. For the particular narratives, the first focused on a young woman and her mother and the efforts made by others to help her in acquiring formal mental health care. The second focused on a young man, whose voice-over is worked into the musical score to convey to the audience what he was thinking as he experienced early psychosis-his confusion and withdrawal from friends.

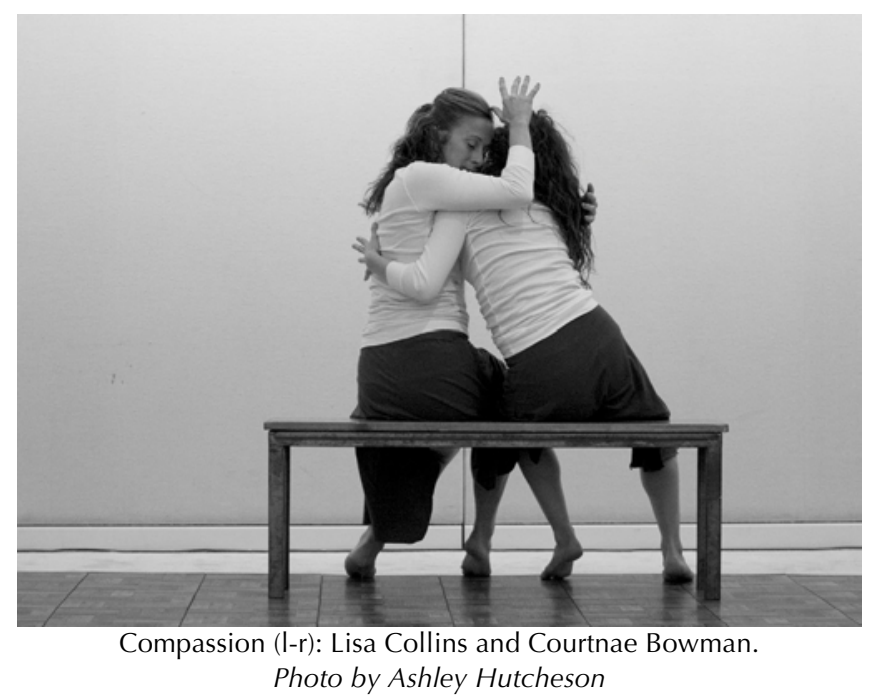

Research team involvement was crucial; it provided feedback regarding the way in which the performance was evolving and shaped the ultimate product. The meetings held between dancers, musician, choreographer, and research team offered a lens into both worlds-dancers were able to ask their questions about the subject matter and the research team could see the ways in which a thematic concept from the study was integrated into the dance movements. At an early rehearsal, the research team commented that the dance (as it was evolving) was too focused on individual psychology and needed to reflect the research findings (which indicated that the help-seeking process was not an individual decision making process, but that there were many significant others involved). The choreographic process then focused more on the relationships between young people with psychosis and the impact of others in their lives. For example, there was more interaction between the dancers: in one particular case, a young woman and her mother embraced each other while sitting on a bench. In another dance sequence, a young man and woman demonstrated their connection through outstretched hand movements. This process demonstrated aspects of the evolving perspectives on ways of presenting the data on youth with first episode psychosis. 
Using Performative Art to Communicate Research: Dancing Experiences of Psychosis

In exploring the potential of alternate forms of representation to highlight the worlds we wish to understand it is important to measure audience response. In a transdisciplinary world, we operate outside traditional boundaries and disclose moments that may be hard to define or categorize by engaging with new experiences and improvising unconventional combinations of knowledge. The dance has been presented to a wide range of audiences including academics, service providers, policy makers, educators, students, dance choreographers, and the general public. Audience engagement and dialogue were elicited via in-theatre observation of audience responses, moderated post-performance audience discussions, audience feedback in the form of Post-it notes, and researcher field notes. Analysis of this data suggests that dance is an effective way to disseminate empirical research results and to enhance awareness and understanding of the phenomena being studied. It also highlights the importance of the aesthetic qualities and visceral impact of the performance.

Viewing the co-creation of a research-based dance allowed us to study the process of dance creation and its capacity to convert abstract research into concrete form and produce generalizable knowledge from empirical research findings. Thus, through the techniques of movement, metaphor, voiceover, and music, the characterization of experience in the dance was personal and generic, individual and collective, particular and trans-situational. The dance performance allowed us to address the visceral, emotional, and visual aspects of our research which are frequently invisible in traditional academia. This paper provides a detailed analysis of the processual and emergent nature of co-creating a researchbased dance performance, while paying close attention to the unfolding of intersubjective and multiperspectival elements. By focusing on this form of knowledge production, we hope to inspire further research on the use of the arts as a mechanism of both knowledge creation and knowledge dissemination.

\section{Notes}

1. For more on the significance of collaborations between social scientists and artists, see D. Horsfall and A. Titchens' "Disrupting Edges-Opening Spaces: Pursuing Democracy and Human Flourishing Through Creative Methodologies" in International Journal of Social Research Methodology (12.2 [2009]: 147-160) and Kip Jones' "A Biographic Researcher in Pursuit of an Aesthetic: The Use of Arts-Based (Re)Presentations in 'Performative' Dissemination of Life Stories" in Qualitative Sociology Review (2.1 [2006]: 66-85).

2. See K.M. Boydell, B. Gladstone, J. Addington, P. Goering, E. McCay, T. Krupa, E. Stasiulis, and T. Volpe, "Youth Experiencing First Episode Psychosis: A Comprehensive Examination of Pathways to Mental Health" in Schizophrenia Research (86 [2006]: S116); K.M. Boydell, B. Gladstone, and T. Volpe, "Understanding Help-Seeking Delay in First Psychosis Prodrome: A Secondary Analysis of the Perspectives of Young People" in Schizophrenia Research (86 [2006a]: S124); K.M. Boydell, B. Gladstone, and T. Volpe, "Understanding Help Seeking Delay: Perspectives of Youth Experiencing First Episode Psychosis" in Psychiatric Rehabilitation Journal (30.1 [2006b]: 54-60); and B. Gladstone, T. Volpe, K.M. Boydell, "Issues Encountered in a Qualitative Secondary Analysis of Help-Seeking in the Prodrome to Psychosis" in Journal of Behavioral Health Services \& Research (34.4 [2007]: 431-442). 
3. See, for example, Julia Gray's "Exploring the Creative and Academic Tensions in Developing After the Crash : a play about brain injury - a research-based theatre project about traumatic brain injury" (MA thesis, York U, 2007); Kate Rossiter, Julia Gray, Pia Kontos, Michelle Keightly, Angela Colantonio, and Julie Gilbert, "From Page to Stage: Dramaturgy and the Art of Disciplinary Translation" in Journal of Health Psychology (13.2 [2008]: 277-286); and Johnny Saldana, "Dramatizing the Data: A Primer" in Qualitative Inquiry (9.2 [2003]: 218-236).

4. See B. Gladstone, T. Volpe, and K.M. Boydell's "Issues encountered in a qualitative secondary analysis of help-seeking in the prodrome to psychosis" in Journal of Behavioral Health Services \& Research (34:4 [2007]: 431-442).

5. See Kate Rossiter, Julia Gray, Pia Kontos, Michelle Keightly, Angela Colantonio, and Julie Gilbert's "From Page to Stage: Dramaturgy and the Art of Disciplinary Translation" in Journal of Health Psychology (13.2 [2008]: 277-286).

\section{Works Cited}

Bagley, Carl and Mary Beth Cancienne. "Educational Research and Intertextual Forms of (Re)presentation: The Case for Dancing the Data." Qualitative Inquiry 7.2 (2001): 221-37. Print.

Boydell, Katherine M., Brenda Gladstone, Jean Addington, Paula Goering, Elizabeth McCay, Terry Krupa, Elaine Stasiulis, and Tiziana Volpe. "Youth Experiencing First Episode Psychosis: A Comprehensive Examination of Pathways to Mental Health." Schizophrenia Research 86 (2006): S116. Print.

Boydell, Katherine M., Brenda Gladstone, and Tiziana Volpe. "Understanding Help-Seeking Delay in First Psychosis Prodrome: A Secondary Analysis of the Perspectives of Young People." Schizophrenia Research 86 (2006a): S124. Print.

—. "Understanding Help Seeking Delay: Perspectives of Youth Experiencing First Episode Psychosis." Psychiatric Rehabilitation Journal 30.1 (2006b): 54-60. Print.

Boydell, Katherine M. and Siona Jackson. Research-Based Dance as a Knowledge Translation Strategy. Ottawa: CIHR Knowledge Translation Casebook, 2010. Print.

Boydell, Katherine M., Siona Jackson, and J.S. Strauss. "Help Seeking Experiences of Youth with First Episode Psychosis: A Research-Based Dance Production." Hearing Voices: Qualitative Inquiry in Early Psychosis. Eds. Katherine M. Boydell and H.B. Ferguson. Waterloo, ON: Wilfrid Laurier UP (at press).

Denzin, Norman K. "The Call to Performance." Symbolic Interaction 26.1 (2003): 187-207. Print.

Gadamer, Hans G. Truth and Method. New York: Seabury Press,1975. Print.

Gladstone, Brenda, Tiziana Volpe, and Katherine M. Boydell. "Issues Encountered in a Qualitative Secondary Analysis of Help-Seeking in the Prodrome to Psychosis." Journal of Behavioral Health Services \& Research 34.4 (2007): 431-42. Print.

Gray, Julia. "Exploring the Creative and Academic Tensions in Developing After the Crash: a play about brain injury — a research based theatre project about traumatic brain injury." MA thesis. York $U$, 2007. Print. 
Horsfall, Debbie and Angie Titchens. "Disrupting Edges-Opening Spaces: Pursuing Democracy and Human Flourishing Through Creative Methodologies." International Journal of Social Research Methodology 12.2 (2009): 147-60. Print.

Jones, Kip. "A Biographic Researcher in Pursuit of an Aesthetic: The Use of Arts-Based (Re)Presentations in 'Performative' Dissemination of Life Stories." Qualitative Sociology Review 2.1 (2006): 66-85. Print.

Rossiter, Kate, Julia Gray, Pia Kontos, Michelle Keightly, Angela Colantonio, and Julie Gilbert. "From Page to Stage: Dramaturgy and the Art of Disciplinary Translation." Journal of Health Psychology 13.2 (2008): 277-86. Print.

Saldana, Johnny. "Dramatizing the Data: A Primer." Qualitative Inquiry 9.2 (2003): 218-36. Print.

Todres, Les. Embodied Inquiry: Phenomenological Touchstones for Research, Psychotherapy and Spirituality. New York: Palgrave Macmillan, 2007. Print.

\section{Acknowledgments}

Sincere thanks are extended to the creative team (Siona Jackson, Tim Isherwood, Jeff Dimitrou, Nicola Pantin, Mariano Abarca, Shavar Blackwood, Courtnae Bowman, and Lisa Collins) and research team (Brenda Gladstone, Elaine Stasiulis, and Tiziana Volpe) involved in this co-creation, as well as the photographer Ashley Hutcheson.

This research was made possible by the Canadian Institutes of Health Research (CIHR).

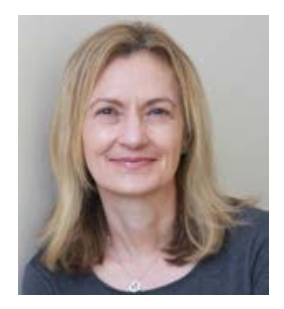

Katherine M. Boydell is a Professor of Mental Health at The Black Dog Institute, University of New South Wales. Her substantive research focuses on understanding the complex pathways to care for young people experiencing mental ill health, the use of new technologies in child and youth mental health, and the "science" of knowledge translation, while her methodological research examines the advancement of qualitative inquiry, specifically, in the study of arts-based health. She has used documentary film, research-based dance, digital storytelling, body mapping, photovoice, and found poetry in her program of research. She has published more than 200 journal articles and published the only text on qualitative inquiry in the field of early psychosis titled, Hearing Voices: Qualitative Inquiry in Early Psychosis. Hearing Voices (www.sandboxinc.ca/livecreation) represents a 15-minute performative piece (co-created with researchers, dance choreographers, and musician) based on 60 in-depth narratives of the pathways to care of young people affected by first episode psychosis. This research-based dance was funded by the Canadian Institutes of Health Research. 
Katherine Boydell

86 | LEARNing Landscapes | Spring 2020, Vol. 13 